\title{
It is not power, but how you use it: Experimental evidence on altruism in the household from Pakistan*
}

\author{
Farah Said, Mahreen Mahmud $\$$ Giovanna d'Adda ${ }^{\S}$ \\ and Azam Chaudhry ${ }^{\mathbb{I}}$
}

May 8, 2019

\begin{abstract}
We investigate altruism among household members in the presence of information asymmetry using artefactual experiments in Pakistan. Having a family member who does not respect one's control over earned property makes generosity less likely within the experiment. Women, who display greater entitlement over own earnings, are less generous when they can conceal their allocation decisions, showing that self-regarding behaviors are driven by pent-up demand for household members to respect their control over resources. Our findings reveal that understanding household dynamics can be critical for policy makers wanting to maximize welfare outcomes in social protection programs.
\end{abstract}

Keywords: household decision making; field experiment; altruism; opportunism; respect JEL codes: C93, D13, D82, J16, O12

*This project was funded by the International Growth Centre and was only possible with the support of Zara Murtaza, Kamran Azim (Kashf Foundation, Pakistan); and Dr. Naved Hamid (Lahore School of Economics). The study received Institutional Review Board approval from the Lahore School of Economics RERC on $24^{\text {th }}$ April 2015.

${ }^{\dagger}$ Lahore School of Economics (farahs@lahoreschool.edu.pk). Corresponding author.

†University of Oxford (mahreen.mahmud@economics.ox.ac.uk)

§University of Milan (giovanna.dadda@unimi.it)

ILahore School of Economics (azam@lahoreschool.edu.pk) 


\section{Introduction}

Modern social protection programs, such as the Bolsa Família in Mexico, the Benazir Income Support Programme in Pakistan, and food stamp schemes in India and Sri Lanka, have made a purposeful shift towards making women the recipients of transfers. However, recent evidence has found that targeted grant programs do not always have the intended distributional effects on the household (see Duflo (2012) for a review). One possible reason for this is that these programs strongly rely on the assumption of efficient intra-household decision-making, which in turn relies on household members being benevolent towards each other.

While some authors have found that information asymmetries reduce altruism towards household members, and thus efficiency of intra-household allocations (Kebede et al., 2014; Castilla, 2015), very little is known about other sources of altruistic behavior among household members. Filling this gap has important implications for the targeting and design of transfer programs: for instance, information on the drivers of intra-household altruism, in particular on the power structure within the household, can inform choices on their mode of delivery - in cash or in kind, public or private- and their recipients (Ashraf, 2009).

In this paper, we examine correlates of altruistic behavior among household members by conducting an artefactual experiment in peri-urban areas of Punjab, Pakistan. The experiment consists of simple tasks, where we vary whether individuals have private information. The tasks generate measures of opportunism and respect among household members. Our study adds to literature that tests systematic differences in altruism in the household (Iversen et al., 2010; Hoel, 2015; Dasgupta and Mani, 2015; Barr et al., 2017). Methodologically, we show how a parsimonious design, easily implementable with a largely illiterate population, can yield meaningful measures of household preferences that correlate significantly with agency outside of the laboratory.

\section{Experimental design and implementation}

The experiment was conducted in peri-urban areas of Punjab, Pakistan. Our sample consists of 267 women, selected randomly from a pool of microfinance applicants and invited to participate in the experiment with husbands (if married) or the main male decision makers in their household. Similar to the sample in other impact evaluation studies (for instance, de Brauw et al. (2014)), men are, in general, more educated than the women, with an average of 5 years of education to 3 years of education for women. More than four-fifths of the study sample is married. Women in our sample are either housewives (48\%) or self-employed (36\%), while men predominantly engage in daily $(54 \%)$ or monthly wage 
labor $(23 \%){ }^{1}$ The sample characteristics shown in these summary statistics are typical of low income households in other developing countries (Kebede et al., 2014; de Brauw et al., 2014; Dasgupta and Mani, 2015) and imply that our results are relevant to these other settings.

Each participant was matched with a partner of the opposite gender: half of the subjects were paired with a household member ( $\mathrm{HH}$ member treatment), and the other half with a stranger (Stranger treatment). Male and female sessions were conducted separately but simultaneously. Subjects performed the following tasks, with the order of tasks randomized across sessions. Participants were paid for one randomly selected task at the end of the session. $^{2}$

- Public Dictator Game (henceforth, DG): a standard DG, where subjects allocated a share of PKR 1000 (\$10) endowment (windfall) to their partner, and shares were revealed to the partner.

- Private DG: a DG where allocated share of PKR 1000 (\$10) was not fully revealed to the partner. The experimenter used a coin toss to add or subtract an unknown sum to the allocation, allowing participants' to plausibly deny its exact amount (Hoel, 2015).

- Public DG with earned endowment: a standard DG where the endowment was earned through a real effort task (rather than a windfall provided by the experimenter). We elicit sharing decisions for each possible level of earned endowment.

- Public taking game (henceforth, TG) with earned endowment: the partner earns endowment from a real effort task and subjects decide how much of the partner's earned endowment to take for themselves. We elicit sharing decisions for each possible level of earned endowment.

\section{Results}

\subsection{Variables and hypotheses}

The literature considers individuals to be truly altruistic when they are generous towards others even if their actions are not perfectly observed. On the other hand, individuals can be expected to act opportunistically if their actions cannot be observed by others. We believe

\footnotetext{
${ }^{1}$ A total of 26 sessions in three districts of Punjab: Bahawalpur, Gujrat and Sialkot. Average monthly household income in Gujrat, Bahawalpur and Sialkot are \$520, \$300 and \$290, respectively (Inflation adjusted estimates from PSLM 2010-11). Summary statistics, detailed protocol and instructions are available in the Online Appendix.

${ }^{2}$ Results presented in section 3.2 are robust to task order effects. Participants earned 1400 PKR on average. All payments were in private.
} 
opportunistic behavior under private information to be motivated primarily by the process through which resources have been obtained, and expectations that household members will capture them. We construct three indicators to test this relationship.

- Opportunistic: a variable equal to one if a subject displays lower altruism in the Private DG, when allocations are not fully revealed to partners, than in the Public DG.

- Entitled: we define feeling entitled to one's earned income if a subject keeps more of it in the public DG with earned endowment than in the public DG with windfall.

- Low respect: we define showing low respect for the partner's earnings if a subject takes more from others' earnings than of own earning. That is, if the difference in allocation to self in the public TG and the public DG with earned endowment is positive.

Additionally, we use survey questions on household decision making to construct an index of female agency. ${ }^{3}$

We expect subjects to act less altruistically if they feel vulnerable to capture outside of the experiment. Having a household member who does not respect others' earned property, as measured by behavior within the experiment, and having low decision power within the household are expected to be positively correlated with a subject's feelings of vulnerability, and thus with opportunistic behavior. Having greater agency within the household should be associated with lower opportunism among women. We expect to observe these effects when the household member is also the subject's partner in the task, but not when the subject is matched to a stranger.

\subsection{Results}

Appendix Tables A2 and A3 display summary statistics of the behavioral indices of opportunism, entitlement and respect by gender and match type, and of task behavior, respectively; and Table A4 provides the correlations between the relevant variables for the entire sample, as well as for the male and female samples separately. Overall, opportunism does not significantly differ by gender, while men display less respect for the partner's earnings and significantly greater entitlement to their own earned income than women, especially in the household partner treatment $\left(\mathrm{p}=0.0546\right.$, two-sided t-test). ${ }^{4}$ The correlation matrix shows that there is no significant collinearity between the variables selected.

We test the role of the various correlates of opportunism by regressing the opportunism indicator on the indices of entitlement, low respect and household agency. We also examine how these correlations vary when subjects face a household member by interacting these

\footnotetext{
${ }^{3}$ The Online Appendix shows the full list of questions on female agency asked in the survey and describes how the agency index used in the analysis is constructed.

${ }^{4}$ These results are also presented graphically in Appendix Figure A1.
} 
indices with a dummy equal to one for subjects in the $\mathrm{HH}$ partner treatment. Table 1 presents regression results.

Table 1: Experimental correlates of opportunism

\begin{tabular}{|c|c|c|c|}
\hline \multirow[t]{2}{*}{ Dependent variable } & \multicolumn{3}{|c|}{ Opportunistic } \\
\hline & $\begin{array}{l}\text { All } \\
(1)\end{array}$ & $\begin{array}{c}\text { Female } \\
(2)\end{array}$ & $\begin{array}{c}\text { Male } \\
(3)\end{array}$ \\
\hline Partner is a household member & $\begin{array}{c}-0.139 * * * \\
(0.0416)\end{array}$ & $\begin{array}{c}-0.213 * * * \\
(0.0581)\end{array}$ & $\begin{array}{l}-0.0660 \\
(0.0633)\end{array}$ \\
\hline Entitled & $\begin{array}{c}0.0932 \\
(0.0677)\end{array}$ & $\begin{array}{c}0.0634 \\
(0.0998)\end{array}$ & $\begin{array}{c}0.0858 \\
(0.0928)\end{array}$ \\
\hline Household member shows low respect & $\begin{array}{l}-0.0988 * \\
(0.0527)\end{array}$ & $\begin{array}{l}-0.0441 \\
(0.0859)\end{array}$ & $\begin{array}{l}-0.136 * \\
(0.0821)\end{array}$ \\
\hline Female agency & $\begin{array}{c}0.0367 \\
(0.0228)\end{array}$ & $\begin{array}{c}0.0540 \\
(0.0329)\end{array}$ & $\begin{array}{r}0.0280 \\
(0.0320)\end{array}$ \\
\hline Partner is a household member x Entitled & $\begin{array}{l}0.235 * * * \\
(0.0875)\end{array}$ & $\begin{array}{l}0.384 * * * \\
(0.129)\end{array}$ & $\begin{array}{c}0.153 \\
(0.115)\end{array}$ \\
\hline $\begin{array}{l}\text { Partner is a household member x Household } \\
\text { member shows low respect }\end{array}$ & $\begin{array}{l}0.212 * * * \\
(0.0768)\end{array}$ & $\begin{array}{c}0.183 \\
(0.111)\end{array}$ & $\begin{array}{c}0.186 \\
(0.119)\end{array}$ \\
\hline $\begin{array}{l}\text { Partner is a household member } x \text { Female } \\
\text { agency }\end{array}$ & $\begin{array}{c}-0.0697 * * \\
(0.0293)\end{array}$ & $\begin{array}{l}-0.112 * * \\
(0.0444)\end{array}$ & $\begin{array}{l}-0.0372 \\
(0.0425)\end{array}$ \\
\hline Female & $\begin{array}{c}0.0688 \\
(0.0432)\end{array}$ & - & - \\
\hline Constant & $\begin{array}{l}0.339 * * * \\
(0.111)\end{array}$ & $\begin{array}{l}0.416 * * * \\
(0.154)\end{array}$ & $\begin{array}{c}0.300 \\
(0.184)\end{array}$ \\
\hline$N$ & 533 & 267 & 266 \\
\hline$R^{2}$ & 0.181 & 0.293 & 0.241 \\
\hline
\end{tabular}

Note: Table shows OLS regressions with session fixed effects. Standard errors are shown in parentheses, clustered at the pair level in Column 1, robust in Column 2 and 3. All regressions control for age, education, occupation, household assets, giving in the public DG, being household head. $* \mathrm{p}<0.10, * * \mathrm{p}<0.05, * * * \mathrm{p}<0.01$. 
Subjects are generally less opportunistic when matched with a household member, unless the latter displays low respect for others' earned property. This holds for both genders, although we lose significance when we split samples due to the small sample size. Feeling entitled to one's earnings is associated with more opportunistic behavior, while female agency in the household is associated with less opportunistic behavior. Both results are driven by women matched with a household member, which suggests that women, who have less pent up demand for agency in the household, are less opportunistic towards family members. On the contrary, facing a more empowered woman is not associated with higher opportunism among men. ${ }^{5}$ Comparing our results to similar studies, which look at the link between altruism and effort (Dasgupta and Mani, 2015; Barr et al., 2017), we find that our coefficients are comparable both in size and significance to theirs.

\section{Conclusion}

Early tests of household models have shown a strong effect of altruism on whether efficiency gains can be realized. However, the literature has only begun investigating sources of heterogeneity in altruistic behavior in the household. Our results uncover two key enablers of opportunistic behavior among household members - pent-up demand for respect and agency - each affected by power asymmetries and experiences in the household. These results imply that any social protection program that targets specific individuals for grants may fail to improve household welfare, if intra-household power asymmetries are not taken into account in the design of the grant.

\footnotetext{
5 These results are robust to order effects, and to alternative specifications of the low respect and female household agency indicators. For instance, we define Low respect as taking more than 50 per cent of the partner's earned endowment in the TG. Tables B1 an B2 in the Online Appendix present these results.
} 


\section{References}

Ashraf, N. (2009). Spousal control and intra-household decision making: An experimental study in the Philippines. American Economic Review, 99(4):1245-1277.

Barr, A., Dekker, M., Janssens, W., Kebede, B., and Kramer, B. (2017). Cooperation in polygynous households. IFPRI Discussion Paper 1625, International Food Policy Research Institute (IFPRI).

Castilla, C. (2015). Trust and Reciprocity between Spouses in India. American Economic Review, 105(5):621-624.

Dasgupta, U. and Mani, S. (2015). Only mine or all ours: Do stronger entitlements affect altruistic choices in the household. World Development, 67(C):363-375.

de Brauw, A., Gilligan, D. O., Hoddinott, J., and Roy, S. (2014). The impact of bolsa família on womenâĂŹs decision-making power. World Development, 59:487-504.

Duflo, E. (2012). Women empowerment and economic development. Journal of Economic Literature, 50(4):1051-1079.

Hoel, J. B. (2015). Heterogeneous households: A within-subject test of asymmetric information between spouses in Kenya. Journal of Economic Behavior and Organization, 118:123-135.

Iversen, V., Jackson, C., Kebede, B., Munro, A., and Verschoor, A. (2010). Do spouses realise cooperative gains? Experimental evidence from rural Uganda. World Development, 39(4):569578.

Kebede, B., Tarazona, M., Munro, A., and Verschoor, A. (2014). Intra-household efficiency: An experimental study from Ethiopia. Journal of African Economies, pages 1-46. 
Appendix 


\section{Tables}

Table A1: Descriptive statistics of the experiment sample

\begin{tabular}{|c|c|c|c|c|c|c|c|}
\hline & \multicolumn{2}{|c|}{ Male } & \multicolumn{2}{|c|}{ Female } & \multicolumn{2}{|c|}{ Total } & \multirow[t]{2}{*}{ p-value } \\
\hline & Mean & $\mathrm{Sd}$ & Mean & $\mathrm{Sd}$ & Mean & $\mathrm{Sd}$ & \\
\hline Age & 36.32 & (11.91) & 37.20 & (9.328) & 36.76 & (10.69) & 0.341 \\
\hline Married & 0.801 & $(0.400)$ & 0.865 & $(0.342)$ & 0.833 & $(0.373)$ & $0.046 * *$ \\
\hline \multicolumn{8}{|l|}{ Education } \\
\hline Illiterate & 0.303 & $(0.461)$ & 0.513 & $(0.501)$ & 0.408 & $(0.492)$ & $0.000 * * *$ \\
\hline Primary & 0.270 & $(0.445)$ & 0.210 & $(0.408)$ & 0.240 & $(0.427)$ & 0.108 \\
\hline More than primary & 0.225 & $(0.418)$ & 0.210 & $(0.408)$ & 0.217 & $(0.413)$ & 0.664 \\
\hline Years of education & 5.300 & $(4.124)$ & 3.734 & $(4.381)$ & 4.517 & $(4.322)$ & $0.000 * * *$ \\
\hline \multicolumn{8}{|l|}{ Occupation } \\
\hline Housewife & 0.011 & $(0.106)$ & 0.479 & $(0.501)$ & 0.245 & $(0.431)$ & $0.000 * * *$ \\
\hline Self-employed & 0.094 & $(0.292)$ & 0.356 & $(0.480)$ & 0.225 & $(0.418)$ & $0.000 * * *$ \\
\hline Labourer & 0.539 & $(0.499)$ & 0.097 & $(0.297)$ & 0.318 & $(0.466)$ & $0.000 * * *$ \\
\hline Salaried & 0.228 & $(0.421)$ & 0.045 & $(0.208)$ & 0.137 & $(0.344)$ & $0.000 * * *$ \\
\hline \multicolumn{8}{|l|}{ Empowerment } \\
\hline Decide alone & & & 4.85 & $(3.042)$ & & & \\
\hline Allowed work & & & 0.835 & $(0.372)$ & & & \\
\hline Female agency & & & 0.000 & (1.094) & & & \\
\hline$N$ & 267 & & 267 & & 534 & & \\
\hline
\end{tabular}

Note: 'Female agency' is an index, created from Principle Components Analysis, using 'Decide alone' that measures the number of household decisions the respondent can make alone (clothing, footwear, medical, recreation, social visits, joining credit groups, purchases for self, purchases for others, marriage, investment); and a dummy variable for if the respondent is allowed to work by her family members. Age is missing for one male respondent. The remaining data is available for all 267 male respondents. $p$-value in the far right column are from a t-statistic test of the difference in means across gender, after controlling for session fixed effects. $* \mathrm{p}<0.10, * * \mathrm{p}<0.05, * * * \mathrm{p}<0.01$. 
Table A2: Summary statistics of game behaviour

\begin{tabular}{|c|c|c|c|c|c|c|c|c|}
\hline & \multicolumn{2}{|c|}{ Male } & \multicolumn{2}{|c|}{ Female } & \multicolumn{2}{|c|}{ Total } & \multirow[t]{2}{*}{$p$-value } \\
\hline & & Mean & $\mathrm{Sd}$ & Mean & $\mathrm{Sd}$ & Mean & $\mathrm{Sd}$ & \\
\hline \multirow[t]{3}{*}{ Opportunistic } & All & 0.228 & $(0.421)$ & 0.228 & $(0.421)$ & 0.228 & $(0.420)$ & 1.000 \\
\hline & Stranger & 0.206 & $(0.406)$ & 0.244 & $(0.431)$ & 0.225 & (0.419) & 0.461 \\
\hline & $H H$ & 0.250 & $(0.435)$ & 0.213 & $(0.411)$ & 0.232 & $(0.423)$ & 0.477 \\
\hline \multirow[t]{3}{*}{ Entitled } & All & 0.322 & $(0.468)$ & 0.266 & $(0.443)$ & 0.294 & $(0.456)$ & 0.155 \\
\hline & Stranger & 0.305 & $(0.462)$ & 0.267 & $(0.444)$ & 0.286 & $(0.453)$ & 0.496 \\
\hline & $H H$ & 0.338 & $(0.475)$ & 0.265 & $(0.443)$ & 0.301 & $(0.460)$ & 0.188 \\
\hline \multirow[t]{3}{*}{ Low respect } & All & 0.281 & $(0.450)$ & 0.213 & $(0.411)$ & 0.247 & $(0.432)$ & $0.071^{*}$ \\
\hline & Stranger & 0.244 & $(0.431)$ & 0.214 & $(0.412)$ & 0.229 & $(0.421)$ & 0.558 \\
\hline & $H H$ & 0.316 & $(0.467)$ & 0.213 & $(0.411)$ & 0.265 & $(0.442)$ & $0.054 *$ \\
\hline$N$ & & 267 & & 267 & & 534 & & \\
\hline
\end{tabular}

Note: Stranger refers to the sub-group paired with a stranger of the opposite gender. $H H$ refers to the subgroup paired with the household member. Opportunistic is a dummy variable that is 1 if a subject displays lower altruism in the Private DG than in the Public DG, and 0 otherwise; Entitled is a dummy variable that is 1 if a subject keeps more of endowment when it is earned (public DG with earned endowment) than when it is a windfall (public DG), and 0 otherwise; and finally, Low respect is a dummy variable that is 1 when the subject takes more from others' earnings than of own earning, and 0 otherwise. $p$-value in the far right column are from a t-statistic test of the difference in means across gender, after controlling for session fixed effects. $* \mathrm{p}<0.10, * * \mathrm{p}<0.05, * * * \mathrm{p}<0.01$. 
Table A3: Summary statistics of game decisions (Allocations to self in PKR)

\begin{tabular}{lllllllll}
\hline \hline & & \multicolumn{2}{c}{ Male } & \multicolumn{2}{c}{ Female } & \multicolumn{2}{c}{ Total } & p-value \\
& & Mean & Sd & Mean & Sd & Mean & Sd & \\
\hline \multirow{2}{*}{ Public DG } & All & 433.0 & $(222.0)$ & 543.4 & $(189.3)$ & 488.2 & $(213.4)$ & $0.000^{* * *}$ \\
& Stranger & 474.8 & $(225.4)$ & 580.2 & $(183.3)$ & 527.5 & $(211.7)$ & $0.000^{* * *}$ \\
& HH & 392.6 & $(211.7)$ & 508.1 & $(189.0)$ & 450.4 & $(208.5)$ & $0.000^{* * *}$ \\
Private DG & All & 456.9 & $(223.9)$ & 530.7 & $(191.2)$ & 493.8 & $(211.3)$ & $0.000^{* * *}$ \\
& Stranger & 483.2 & $(226.7)$ & 576.3 & $(190.5)$ & 529.8 & $(214.1)$ & $0.000^{* * *}$ \\
& HH & 431.6 & $(219.0)$ & 486.8 & $(182.1)$ & 459.2 & $(202.9)$ & $0.025^{* *}$ \\
& & & & & & & & \\
Earned DG & All & 45.43 & $(17.40)$ & 52.91 & $(10.32)$ & 49.17 & $(14.77)$ & $0.000^{* * *}$ \\
& Stranger & 47.87 & $(16.36)$ & 55.00 & $(10.43)$ & 51.43 & $(14.15)$ & $0.000^{* * *}$ \\
& HH & 43.08 & $(18.11)$ & 50.89 & $(9.819)$ & 46.99 & $(15.05)$ & $0.000^{* * *}$ \\
& & & & & & & & \\
Earned TG & All & 44.88 & $(16.07)$ & 51.64 & $(12.14)$ & 48.26 & $(14.63)$ & $0.000^{* * *}$ \\
& Stranger & 44.51 & $(15.20)$ & 53.46 & $(10.75)$ & 48.99 & $(13.89)$ & $0.000^{* * *}$ \\
& HH & 45.24 & $(16.92)$ & 49.88 & $(13.14)$ & 47.56 & $(15.30)$ & $0.012^{* * *}$ \\
& & & & & & & & \\
\hline \hline
\end{tabular}

Note: Stranger refers to the sub-group paired with a stranger of the opposite gender. $H H$ refers to the subgroup paired with the household member. All amounts refer to the amount that the participant keeps for self when allocating endowment or earnings in PKR $(1 \mathrm{PKR} \approx \$ 1)$. 'DG' are allocations in the dictator games. Earned $D G$ is the share of own earnings allocated to self (over amount PKR 0 - 1000) on average in the dictator game, Earned $T G$ is the share of partner's earning taken for self on average in the taking game. $p$-value in the far right column are from a t-statistic test of the difference in means across gender, after controlling for session fixed effects. $* \mathrm{p}<0.10, * * \mathrm{p}<0.05, * * * \mathrm{p}<0.01$. 
Table A4: Correlation matrix of variables of interest

\begin{tabular}{lcccc}
\hline \hline Panel (a): Males & $\begin{array}{c}\text { Partner is a } \\
\text { household member }\end{array}$ & Entitled & $\begin{array}{c}\text { Partner shows } \\
\text { low respect }\end{array}$ & $\begin{array}{c}\text { Female } \\
\text { agency }\end{array}$ \\
\hline Partner is a & 1.000 & & & \\
household member & $()$. & & & \\
Entitled & 0.035 & 1.000 & & \\
& $(0.576)$ & $()$. & & \\
Partner shows & -0.001 & -0.007 & 1.000 & $()$. \\
low respect & $(0.992)$ & $(0.909)$ & $()$. & \\
Female agency & -0.040 & 0.033 & 0.059 & 1.000 \\
& $(0.513)$ & $(0.957)$ & $(0.335)$ & $()$. \\
\hline \hline
\end{tabular}

\begin{tabular}{lcccc} 
Panel (b): Females & $\begin{array}{c}\text { Partner is a } \\
\text { household member }\end{array}$ & Entitled & $\begin{array}{c}\text { Partner shows } \\
\text { low respect }\end{array}$ & $\begin{array}{c}\text { Female } \\
\text { agency }\end{array}$ \\
\hline Partner is a & 1.000 & & & \\
household member & $()$. & & & \\
Entitled & -0.003 & 1.000 & & \\
& $(0.964)$ & $()$. & & \\
Partner shows & 0.080 & -0.131 & 1.000 & $()$. \\
low respect & $(0.193)$ & $(0.032)$ & 0.018 & 1.000 \\
Female agency & -0.040 & 0.071 & 0.00 \\
& $(0.513)$ & $(0.245)$ & $(0.769)$ & $()$. \\
\hline \hline
\end{tabular}

\begin{tabular}{lcccc} 
Panel (c): Total & $\begin{array}{c}\text { Partner is a } \\
\text { household member }\end{array}$ & Entitled & $\begin{array}{c}\text { Partner shows } \\
\text { low respect }\end{array}$ & $\begin{array}{c}\text { Female } \\
\text { agency }\end{array}$ \\
\hline Partner is a & 1.000 & & & \\
household member & $()$. & & & \\
Entitled & 0.017 & 1.000 & & \\
& $(0.700)$ & $()$. & & \\
Partner shows & 0.041 & -0.074 & 1.000 & $()$. \\
low respect & $(0.340)$ & $(0.086)$ & $()$. & \\
Female agency & -0.040 & 0.036 & 0.038 & 1.000 \\
& $(0.354)$ & $(0.402)$ & $(0.387)$ & $()$. \\
\hline \hline
\end{tabular}

Note: The table provides correlations between main variables of interest shown in Table 1, separately for the sample of male, female and all respondents. $p$-values given in parenthesis.

$* \mathrm{p}<0.10, * * \mathrm{p}<0.05, * * * \mathrm{p}<0.01$. 


\section{Figures}

Figure A1: Main experimental measures, by gender and match type
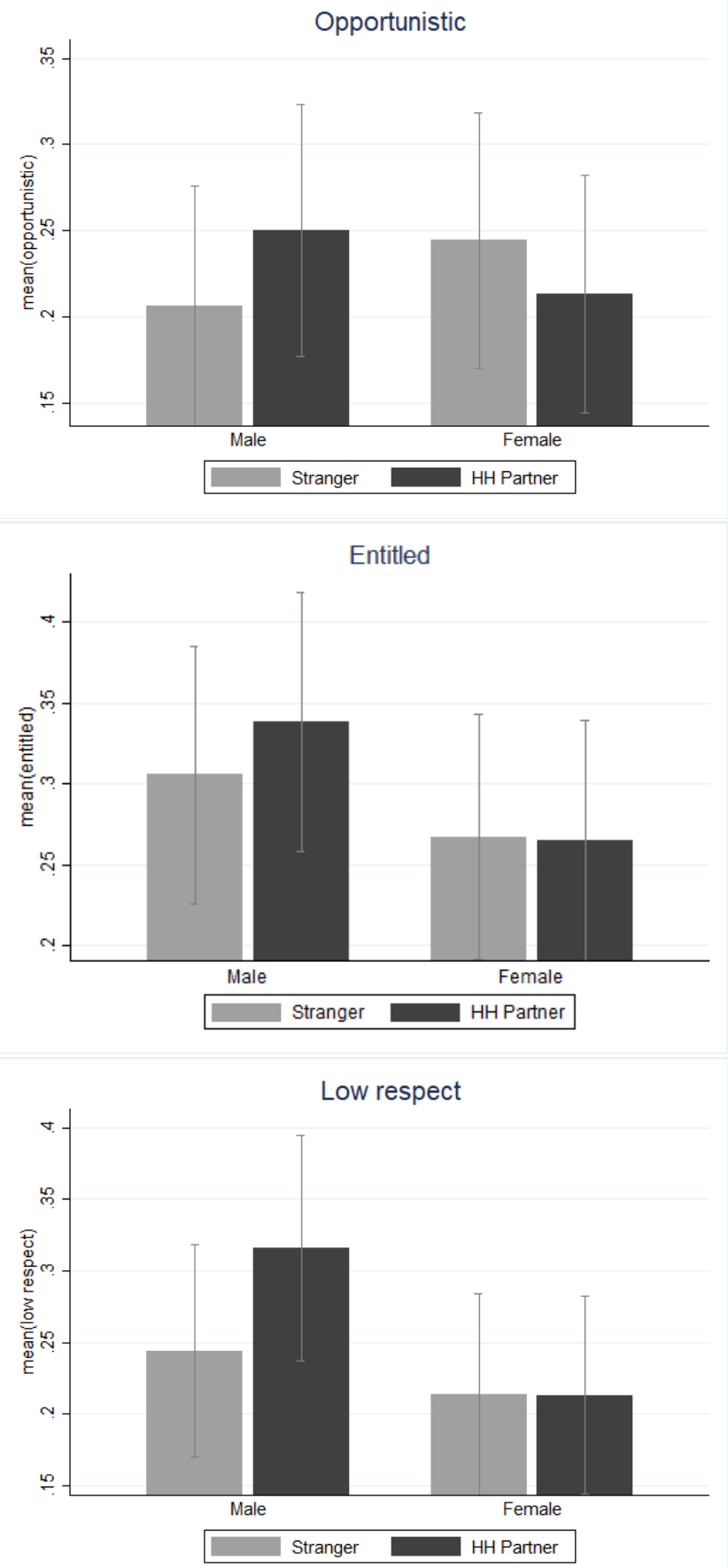

Note: Bars indicate means, whiskers show 95\% confidence intervals. 


\section{Online Appendix}


Table B1: Experimental correlates of opportunism: Controlling for game order

\begin{tabular}{|c|c|c|c|}
\hline \multirow[t]{2}{*}{ Dependent variable } & \multicolumn{3}{|c|}{ Opportunistic } \\
\hline & $\begin{array}{l}\text { All } \\
(1)\end{array}$ & $\begin{array}{l}\text { Female } \\
\text { (2) }\end{array}$ & $\begin{array}{l}\text { Male } \\
(3)\end{array}$ \\
\hline Partner is a household member & $\begin{array}{c}-0.139 * * * \\
(0.0416)\end{array}$ & $\begin{array}{c}-0.213 * * * \\
(0.0581)\end{array}$ & $\begin{array}{l}-0.0660 \\
(0.0633)\end{array}$ \\
\hline Entitled & $\begin{array}{c}0.0932 \\
(0.0677)\end{array}$ & $\begin{array}{c}0.0634 \\
(0.0998)\end{array}$ & $\begin{array}{c}0.0858 \\
(0.0928)\end{array}$ \\
\hline Household member shows low respect & $\begin{array}{l}-0.0988^{*} \\
(0.0527)\end{array}$ & $\begin{array}{l}-0.0441 \\
(0.0859)\end{array}$ & $\begin{array}{l}-0.136^{*} \\
(0.0821)\end{array}$ \\
\hline Female agency & $\begin{array}{c}0.0367 \\
(0.0228)\end{array}$ & $\begin{array}{c}0.0540 \\
(0.0329)\end{array}$ & $\begin{array}{c}0.0280 \\
(0.0320)\end{array}$ \\
\hline Partner is a household member $\mathrm{x}$ Entitled & $\begin{array}{c}0.235^{* * *} \\
(0.0875)\end{array}$ & $\begin{array}{c}0.384 * * * \\
(0.129)\end{array}$ & $\begin{array}{c}0.153 \\
(0.115)\end{array}$ \\
\hline $\begin{array}{l}\text { Partner is a household member } x \text { Household } \\
\text { member shows low respect }\end{array}$ & $\begin{array}{c}0.212 * * * \\
(0.0768)\end{array}$ & $\begin{array}{c}0.183 \\
(0.111)\end{array}$ & $\begin{array}{c}0.186 \\
(0.119)\end{array}$ \\
\hline $\begin{array}{l}\text { Partner is a household member } x \text { Female } \\
\text { agency }\end{array}$ & $\begin{array}{c}-0.0697 * * \\
(0.0293)\end{array}$ & $\begin{array}{l}-0.112 * * \\
(0.0444)\end{array}$ & $\begin{array}{c}-0.0372 \\
(0.0425)\end{array}$ \\
\hline Female & $\begin{array}{c}0.0688 \\
(0.0432)\end{array}$ & - & - \\
\hline $\begin{array}{l}\text { Order in which games are played } \\
\text { in the session }\end{array}$ & $\begin{array}{c}0.0123 \\
(0.0248)\end{array}$ & $\begin{array}{c}0.0111 \\
(0.0352)\end{array}$ & $\begin{array}{c}0.0149 \\
(0.0380)\end{array}$ \\
\hline Constant & $\begin{array}{c}0.265^{* *} \\
(0.127)\end{array}$ & $\begin{array}{c}0.350 \\
(0.218)\end{array}$ & $\begin{array}{c}0.211 \\
(0.165)\end{array}$ \\
\hline $\begin{array}{l}N \\
R^{2}\end{array}$ & 533 & 267 & 266 \\
\hline$R^{2}$ & 0.181 & 0.293 & 0.241 \\
\hline
\end{tabular}

Note: Table shows OLS regressions with session fixed effects. Standard errors are shown in parentheses, clustered at the pair level in Column 1, robust in Column 2 and 3. All regressions control for age, education, occupation, household assets, giving in the public DG, being household head. $* \mathrm{p}<0.10, * * \mathrm{p}<0.05, * * * \mathrm{p}<0.01$. 
Table B2: Experimental correlates of opportunism: Using alternative definition for 'low respect'

\begin{tabular}{|c|c|c|c|}
\hline \multirow[t]{2}{*}{ Dependent variable } & \multicolumn{3}{|c|}{ Opportunistic } \\
\hline & $\begin{array}{l}\text { All } \\
(1)\end{array}$ & $\begin{array}{c}\text { Female } \\
\text { (2) }\end{array}$ & $\begin{array}{l}\text { Male } \\
\text { (3) }\end{array}$ \\
\hline Partner is a household member & $\begin{array}{c}-0.120 * * * \\
(0.0428)\end{array}$ & $\begin{array}{c}-0.164 * * * \\
(0.0601)\end{array}$ & $\begin{array}{l}-0.0924 \\
(0.0644)\end{array}$ \\
\hline Entitled & $\begin{array}{c}0.101 \\
(0.0678)\end{array}$ & $\begin{array}{c}0.0658 \\
(0.0977)\end{array}$ & $\begin{array}{c}0.0827 \\
(0.0923)\end{array}$ \\
\hline $\begin{array}{l}\text { Household member shows low respect } \\
\text { (share to self in } T G>50 \% \text { ) }\end{array}$ & $\begin{array}{l}-0.0715 \\
(0.0575)\end{array}$ & $\begin{array}{c}0.0521 \\
(0.0951)\end{array}$ & $\begin{array}{l}-0.168 * * \\
(0.0759)\end{array}$ \\
\hline Female agency & $\begin{array}{c}0.0357 \\
(0.0229)\end{array}$ & $\begin{array}{c}0.0487 \\
(0.0323)\end{array}$ & $\begin{array}{c}0.0277 \\
(0.0320)\end{array}$ \\
\hline Partner is a household member $\mathrm{x}$ Entitled & $\begin{array}{l}0.222 * * \\
(0.0878)\end{array}$ & $\begin{array}{l}0.366 * * * \\
(0.129)\end{array}$ & $\begin{array}{c}0.146 \\
(0.115)\end{array}$ \\
\hline $\begin{array}{l}\text { Partner is a household member } x \text { Household } \\
\text { member shows low respect }\end{array}$ & $\begin{array}{c}0.150 * \\
(0.0824)\end{array}$ & $\begin{array}{l}0.0372 \\
(0.116)\end{array}$ & $\begin{array}{c}0.244 * * \\
(0.121)\end{array}$ \\
\hline $\begin{array}{l}\text { Partner is a household member x Female } \\
\text { agency }\end{array}$ & $\begin{array}{c}-0.0700 * * \\
(0.0299)\end{array}$ & $\begin{array}{c}-0.107 * * \\
(0.0450)\end{array}$ & $\begin{array}{l}-0.0392 \\
(0.0434)\end{array}$ \\
\hline Female & $\begin{array}{c}0.0707 \\
(0.0435)\end{array}$ & - & - \\
\hline Constant & $\begin{array}{c}0.311 * * * \\
(0.111)\end{array}$ & $\begin{array}{c}0.373 * * \\
(0.152)\end{array}$ & $\begin{array}{l}0.304 * \\
(0.180)\end{array}$ \\
\hline$N$ & 533 & 267 & 266 \\
\hline$R^{2}$ & 0.175 & 0.286 & 0.250 \\
\hline
\end{tabular}

Note: Table shows OLS regressions with session fixed effects. Standard errors are shown in parentheses, clustered at the pair level in Column 1, robust in Column 2 and 3. All regressions control for age, education, occupation, household assets, giving in the public DG, being household head. $* \mathrm{p}<0.10, * * \mathrm{p}<0.05, * * * \mathrm{p}<0.01$. 


\section{Experiment timeline}

Two sessions were conducted in each of the 13 branches for a total of 26 sessions between August and September 2015. Both sessions in one branch area were held on the same day to minimize chances of information spill-over between participants. ${ }^{6}$ Each session was held in a central location close to the local branch and to the residences of the participants. Given the location of Kashf branches, this could mean a distance of 10 to $15 \mathrm{~km}$ between participant residence and the site of experiments. The participation fee was set to be more than sufficient to cover transport costs by any means whether public or privately hired.

Participation was capped at a maximum of 12 couples per session to ensure that the logistics of each session were easily managed. In case more than 12 couples were present for a session, a ballot was conducted to select the 12 couples who would participate; others were asked to leave and paid the participation fee as promised.

The sequence of events during experiment sessions is as follows:

1. Upon arrival, subject pairs are seated in the main hall for the start of general instructions. At this point they are informed that they will be paid participation fee plus their earnings from the activities at the end of the session.

2. In case more than 12 pairs show up for the session, a ballot would be conducted to choose 12 pairs. $70.4 \%$ of the participants attended the sessions with their husband and $29.5 \%$ of the respondents attended with other male members of the household (son, father, brother, etc.)

3. Once 12 pairs have been selected to participate in the session, each pair would retrive a token from an opaque bag that would be their session ID. Tokens 1-6 were red in color; 7-12 were blue (the purpose of this coloring was explained later).

4. Subject pairs were then taken to their respective rooms, men in one room and women in another. No contact is allowed between subjects of opposite genders during the entire experiment. Activities are conducted simultaneously in both rooms.

5. Subjects of the same gender are seated in sequence of their ID tags. There are two rows of chairs spaced apart. Contact between subjects in the same room is strongly discouraged. To help logistics and data entry, participants with ID 1 - 6 are seated on one side, while 7 - 12 are seated on the other.

6. 2 enumerators were solely responsible for entering participant decisions; one for each room. Data was entered on excel sheets designed by the research team and was done

\footnotetext{
${ }^{6}$ In each branch area, surveys were conducted during the week, with experiment sessions conducted only on Sundays. All sessions were held on a Sunday so that working participants, particularly the men, were able to easily attend. Further, separate sessions were held for control and treatment participants of the RCT to minimise the likelihood of participants of the two sessions communicating with each other. Morning and afternoon sessions were randomly allocated to control or treatment clients to avoid any time-of-the-day effects biasing results.
} 
immediately upon the completion of an activity/round in each room.

Table B3: Activity order

\begin{tabular}{cc}
\hline Game Order & Session No. \\
\hline D-R-TD & $11,13,14,16,25$ \\
D-TD-R & $3,9,10,17$ \\
R-D-TD & $2,6,12,26$ \\
R-TD-D & $4,5,8,15,20$ \\
TD-D-R & $1,7,22,24$ \\
TD-R-D & $18,19,21,23$ \\
\hline
\end{tabular}

7. The three activities are played. For dictator and taking activities (D and TD), each subject pair is randomly assigned to stranger and household member/spouse pairing. Earlier, individuals picked out their pair ID out of an opaque bag. Pairs with a red tag (tag ID 1 - 6), were partnered with their household member and those with blue tags were paired with strangers (of the opposite gender). Each pairing is done without replacement, which means all participants in the stranger pairing were paired with one partner only. $51 \%$ of the participants were paired with family member and $49 . \%$ are paired with a stranger.

8. At the end of the session, in each room, the enumerator would invite one participant to pick a number from an opaque bag. The number drawn out would determine which activity of the day was picked for payment. Then, for activities with multiple round, another ballot would determine the round, and then which room's decision (e.g. self or partner's allocations in the dictator and taking games) would be implemented for payment.

9. A short questionnaire was administered to the male participants.

10. Show-up fee + pay off from randomly selected activity was paid to each participant, independently and privately. Participants were not informed what their partners or members of household have earned. 


\section{Experiment script}

The full protocol used in the experiment is as below. The entire script was administered to participants in Urdu and local languages - Saraiki for Bahawalur and Punjabi for Gujrat and Sialkot. Square brackets [] contain instructions for enumerators.

Thank you all for taking the time to be here today. My name is [experimenter's name], and I will be facilitating this meeting. Helping me today, we also have here [introduce everyone]. Before we start, we would like to remind you that we will give you Rs. 1000 each as a compensation for your time, if you decide to participate for the entire duration of the session. These Rs. 1000 are not a part of the activity and are yours to keep. We will give each of you these Rs.1000 at the end of the meeting, together with any other sum you will earn through the activities.

\section{Purpose}

- Today, we will conduct a few activities. We are conducting these activities on behalf of Lahore School of Economics, a private university in Lahore.

- These activities are for research purpose only. The results of the study may eventually be published or part of a book.

- The purpose of these activities is to better understand how people in this community make decisions.

- The results of the study may eventually be published or part of a book.

- It is not part of a development project of any sort.

\section{Activities}

We will perform several activities here today. At the end of all the activities, we will determine your total payoff by randomly selecting one activity for payment. So you have to be very careful to choose exactly what you want each time you take a decision, because that decision may determine your payment at the end. Is this clear to everyone? Do you have questions on this?

The participants will be performing some activities in exchange for real money that they will be able to take home. You should understand that this is not my money. It is money given to me by Lahore School, to use to conduct a research study. As we told you when we invited you to come her, the meeting may take 2 hours, so if you think you will not be able 
to stay that long without leaving please let us know now. Those of you who cannot stay may leave now. Thank you all for taking the time to come today.

[If more than 12 couples show up to participate:]

- We only need 24 individuals to participate in these activities. Thus, unfortunately, not all of you will be able to participate.

- We will have a lottery to determine who will participate.

- To complete the lottery, we will take the coupon you came with today, which has your name on it, and fold the coupon in half.

- Next, we will place your folded coupon of paper in this bag.

- This means that we need one coupon for each couple present here today.

- We will then ask one of you to draw 12 pieces of paper from this bag containing your coupons.

- Those whose names will be drawn will stay here and participate in the activities, while the others will go home.

Is this clear to everyone? Does anyone have any questions on how we will select the 24 participants? [Enumerator: conduct ballot]

Those of you, whose names have not been called, can leave now. Thank you all for taking the time to come today.

[Pay show up fee to all subjects who have to leave (hand out pre-prepared envelopes containing Rs.1000 and have them sign a receipt). Then, after people have left, proceed]

We will now ask you to draw a number tag from this bag. This number tag will determine your ID for the activities. You are given an ID to preserve your anonymity: your name will not be kept anywhere in our records, only your ID.

\section{Consent}

Before we begin, I will explain the basic activities we will do together, and the rules that we will follow.

[Read Consent Statement] If you wish to participate, please say, 'I do' If you do not wish to participate, please advise us. You will be free to leave then. You will not be able to stay in the activity room(s) if you do not wish to participate.

We will now take all women to one room, and all men to another room. Please follow [Assistant's name] to Room 1 if you are a man, or [Assistant's name] to Room 2 if you are a woman. 
[Take the selected participants into the rooms and have them sit. Assistants should direct each subject to her allocated seat. The room number should be displayed on the door so that it is clearly visible]..

[To the participants]

\section{Introduction}

Welcome, and thank you again.

- Before we proceed any further, let me stress something that is very important. Many of you were invited here without understanding very much about what we are planning to do today. If at any time you find that this is something that you do not wish to participate in for any reason, you are of course free to leave at anytime. If you do choose to leave, you won't be able to come back into the activity room(s) until everyone if finished performing all the activities.

- Before we start, please make sure your mobile phones are switched off, to avoid interruptions during the meeting.

- If you have heard about activities that have been conducted here in the past you should try to forget everything that you have been told. These are completely different activities.

- Please also be advised, there are no right or wrong choices, so you should choose whatever you think is best for yourself and not look at your neighbor's choices.

- It is important to remember that not everyone will win the same amount in the activities. Your final earnings will depend on your decisions and on the decisions of others. Everyone will still receive the Rs. 1000 payment for participation, regardless of how much you earn in the activities

- We are about to begin. It is important that you listen as carefully as possible to the instructions, because only people who understand the activities will actually be able to perform them. I will run through some examples to make sure you understand. The examples that we will show you are just to illustrate you the activities, they are in no way indications of how you should perform the activity.

- I will read through a script to explain all the activities that we will perform here today. As you may know, these activities are conducted on other days beside this, so it is very important that people every day receive exactly the same information, and this is the reason why I must read from this script. 


\section{No talking}

- I will now say something very important. You cannot ask questions out loud or talk about the activities with anyone else while we are here together.

- If you need to ask a question at any time, please raise your hand and I will come to you so I can answer your question privately.

- I will explain the activities, do demonstrations, and let you practice the activities before we perform them for real. These demonstrations and practices are to help you understand the rules and clarify any questions.

- Please be sure that you obey these rules because it is possible for one person to spoil the activities for everyone by talking in front of the group. If this happens, we will not be able to continue forward with the activities today.

- Is this clear to everyone? Does anyone have any questions so far about what will go on today?

[If anyone asks a question out loud, explain again that all questions must be asked in private.]

\section{Real payment}

- In today's activities, you will have the opportunity to receive a cash payment. The amount that you will receive will depend on your decisions and on the decisions of others. It will also depend on what role is selected to be paid, a point I will explain in more detail shortly.

- Remember that at the end of all the activities, we will determine your total earnings by randomly selecting one activity for payment. This means that each activity that you will perform contributes to determining your final earnings.

- Remember also, that in addition to what you will earn from the activities, each of you will receive Rs.1000 for participating in today's meeting. This money is yours, regardless of what happens during the activities. It will be paid to you in cash together with your earnings from the activities.

- It is real money, which you will be allowed to keep for yourself or do what you wish. This money will paid to you in cash at the end of the meeting.

- During the activities you will make your decisions using paper slips [show slips], each representing Rs. 100. These paper slips will be converted into cash when you get paid at the end of the meeting. 


\section{Confidentiality}

- Both your decisions and your payment will be private and confidential. Nobody, apart from a member of our team who will enter data and calculate payment will know what you earned, and he/she will not tell anyone.

- We will put up these partitions between you every time you have to take a decision. You will make your decisions behind the partitions, so that nobody else can see what you decide.

The first three activities or games will be conducted in a randomized order. The order of the games will be set by the research team and will be known by the enumerators before each session. [Enumerator: The order or information that the order was randomized is not disclosed to the participants].

We are now ready to begin with the first activity. Let me remind you that you may not ask questions or talk while you are here in the group. If you have any questions, you may raise your hand and I (the enumerator) or my assistant(s) will come answer your question privately. Please be sure to listen to the instructions carefully.

\section{Risk elicitation}

\section{Announcer:}

I will now explain the next/first activity. Please pay close attention to the instructions. We will also do a demonstration, and let you practice the activity before we play. If anything is unclear, please raise your hand and ask.

This activity is individual, i.e. it is not played in pairs, nor is your earnings dependent on the decisions of others. The objective of this activity is to get the most payoff possible and the payoff is based on your own decisions alone.

\section{[Assistant: distribute cards]}

You have been given a card with 6 options. You will make a choice between these 6 options $(1,2,3,4,5$ or 6$)$. I will explain what these options are in a minute. After you select an option, we will draw a ball from this bag. It has an equal number of red and yellow balls [enumerator: draw out each ball one by one and count the number of red and yellow balls].

So this bag has 5 red balls and 5 yellow balls.

Now let me explain what these options are. Each option has the amount in front of it that you will get depending on if a red or a yellow ball is drawn out. You can see this on your card. [Enumerator: point out the options and the amounts on the card/poster]. 
Let us go over how much you will get from each option depending on if a red or yellow ball is drawn from the bag. Option 1 gives me Rs. 250 if a Red ball is drawn out and Rs. 250 if a yellow ball is drawn out. Similarly, option 2 gives me Rs. 475 if a Red ball is drawn out and Rs. 225 if a yellow ball is drawn out. Option 3 gives you Rs. 600 if a Red ball is drawn out and Rs 200 if a yellow ball is drawn. Option 4 gives you Rs. 750 if a Red ball is drawn out and Rs 150 if a yellow ball is drawn. Option 5 gives you Rs. 950 if a Red ball is drawn out and Rs 50 if a yellow ball is drawn. Finally, Option 6 gives you Rs. 1000 if a Red ball is drawn out and Rs 0 if a yellow ball is drawn. Notice that as we go from option 1 to 6 the difference between what we can get from when a red ball is drawn out and when a yellow ball is drawn out increases.

To summarize first you will chose from option 1 to 6 and then I will draw out a red or yellow ball the bag. This will determine the amount you will get.

Let us look at some examples. For instance, I choose option 2. My assistant will now draw a ball from the bag. [Assistant: draw out a ball] You can see that, because my assistant has drawn a [red/yellow] ball, I will get $[\mathrm{X}]$ points. Lets say instead, I choose option 5. My assistant will now draw a ball from the bag. [Assistant: draw out a ball] You can see that, because my assistant has drawn a [red/yellow] ball, I will get $[\mathrm{X}]$ points.

Does anyone have any questions? If you have any questions, please raise your hand and wait for my assistant to come to you.

Let's play a practice round together to make sure that everyone understands the activity. This practice round is to help your understanding of the activity, and it does not count towards your earnings from this activity.

[Play the practice round. Distribute the sheets to everyone. Explain to them that they should mark the option that they want to choose. Draw a ball from the bag, then go to each person and help him or her identify what he or she has earned].

Does anyone have any questions? [After answering all questions] Okay, let's do the activity. [Distribute the cards].

As we have explained, once all activities have been played, we will randomly select one activity for which you will receive payment. If this activity is chosen, then your earnings from this activity will depend on the option that you selected and whether a red ball or a yellow ball was drawn out.

Please mark your choice from 1 to 6 on the card provided after which we will collect your cards. [Collect cards].

Now I will draw a ball out of this bag to determine what you will get if this activity is selected. [Draw out the ball]. 


\section{Dictator with public and private (secret) rounds}

We are now ready to begin another activity(if the second/third activity)/the first activity. Let me remind you that you may not ask questions or talk while you are here in the group. If you have any questions, you may raise your hand and I or my assistant(s) will come answer your question privately.

\section{Introduction and partner matching}

- This activity is performed by pairs of individuals.

- Each of you will perform this activity with someone from the other room.

- Who your partner will be depends on the color of your number tag that was determined by a random draw earlier.

- Half of you were given a red number tag, the other half a blue number tag. Your partner for this activity is determined by the color of your number tag.

- Those of you who were given a red number tag will be paired with the person they came with to the session today in the other room.

- Those of you who were given a blue number tag will be paired with a stranger in the other room. None of you will know exactly with whom you are paired. Only [researcher's name] knows who is matched with whom, and she/he will never tell anyone.

- In the other room, your partner will be doing the same activities you are.

Do you have questions on who your partner will be in this activity? If you have questions, please raise your hand and I will come to you to answer your question privately.

First we will explain the decisions that you are required to make and it might be a little confusing. Please listen carefully, and if there is anything that you don't understand, please raise your hand and we will explain it again. You will also have a chance to ask any questions you have in private with me to be sure you understand.

I will give you 10 tokens that represent money in a white envelope. [Show the envelope]. Each token is worth Rs.100. We also give you a blue envelope which will be empty. [Show the envelope].

You will be asked to divide the tokens between yourself and a partner. I will explain shortly who this partner is. You can keep all tokens for yourself or you can give some or all to your partner.

For example, you can keep four tokens for yourself and give six to your partner. You will have to put the 4 tokens that you want to keep for yourself in the white envelope and put the 
rest of the 6 tokens in the blue envelope. [Enumerator: demonstrate this]. This will mean that you have kept Rs. 400 for yourself and given Rs. 600 to your partner.

Or you can keep 6 tokens for yourself in the white envelope and give the rest to your partner by putting them in the blue envelope. This will mean you keep Rs. 600 for yourself and give Rs. 400 to your partner.

We will now show you posters that will explain some of the choices that you can make [paste poster somewhere and go over each of them one by one]. In the first example, you keep 2 tokens for yourself and give 8 to your partner. This means that you have kept Rs. 200 for yourself and given Rs. 800 to your partner.In the second example, you keep 0 tokens for yourself and give all 10 to your partner. This means that you have kept nothing for yourself and given all of the Rs. 1000 to your partner. In the third example, you keep 10 tokens for yourself and give nothing to your partner. This means that you have kept Rs. 1000 for yourself and given nothing to your partner.

Lets practice this activity. I have with me 10 tokens. I decide to put 8 of these tokens in the blue envelope. Who is this money going to go to? [Check if answer is partner]. How much are these tokens worth to your partner? [Check if the answer is 800]. How much money have you kept for yourself? [Check if the answer is 200]. Are there any questions? Please raise your hand and I can come to you in private and explain the activity to you.

We will do this activity twice. Both rounds of the activity will be similar;the only difference is that once your decision will be made public and once kept private. That is, in the public round, your partner will know what amount you allocated to them whereas in the private round, your partner will not know what amount you allocated to them. We will let you know which round is public, which is private and how we will make sure your decisions are kept private in the private round.

As we have explained earlier, once all activities have been played, we will randomly select one activity for which you will receive payment by picking out a number from the bag. Once the activity is selected, we will then select a number again from the bag which will determine the round. Then we will select by again picking out a number from the bag whether payments decided in Room 1 or Room 2 will be made. So, this means that if this activity selected, there is an equal chance that you will be paid according to your choices or those made by your partner. Does anyone have any questions?

[To the enumerator: Randomise order of public/secret activities - you do not need to announce that we are now going to randomise order.]

\section{Public round}

Now lets do the first round (if the first round) /Now lets conduct the next round (if not the first round).Your partner in this activity is the same as in the last round. If this activity and 
round is selected, your choices in this round will be made public. That is, your choice will be told to your partner but not to anyone else here. In the other room, your partner will be doing exactly the same activities that you are.

Please note, only the amount you allocated will be made known to the partner. This means, that for those of you who are paired with strangers, will disclose the amount allocated but will not disclose your identity. For those paired with the person they came with to this venue, of course, your partner will know your identity as well.

Let me remind you who your partner is. Those of you who were given a red number tag are paired with the person who they came with to the session today in the other room. Those of you who were given a blue number tag are paired with a stranger in the other room. None of you know exactly with whom you are paired. Only researchers knows who is matched with whom, and she/he will never tell anyone. [To the enumerator: Now conduct the activity. Distribute envelopes].

Please open your white envelopes and count that you all have 10 tokens.

Now put the tokens back in the white envelope.

Remember, because this activity is public, your partner will know how much money you gave and how much you kept for yourself. Please put as many tokens as you want to give to your partner in the blue envelope and put the tokens you want to keep for yourself in the white envelope. Make sure your choice is hidden and do not discuss it with other participants in the room. We will then shortly collect both these envelopes from you. This will tell us how much you have given to your partner. Let me remind you that those of you who were given a red number tag will are paired with the person they came with to the session today in the other room. Those of you who were given a blue number tag are paired with a stranger in the other room.

Are there any questions? Please raise your hand and I can come to you in private and explain the activity to you.

My assistant will now come to you one by one to collect the envelopes. Please keep seated as we do so. As we have explained, once all activities have been played, we will randomly select one activity for which you will receive payment. If this activity is chosen, we will select a number from this bag to select the round and the room according to which payment will be made. [Show numbers and bag].

\section{Secret/private round}

Now let us do the first round (if the first round) /Now let us conduct the next round (if not the first round). Your partner in this activity is the same as in the last round. Your choices in this round will be private. That is, your choice of amount to be allocated will not be told to your partner or anyone else here. 
Let me now explain how we will make sure your choices are private. If this activity and round is selected at the end, the payment we will make to your partner will be determined by what you give him/her plus/minus a pre-decided amount selected by the researcher that neither I nor anyone else in the other room knows. How will the researcher know how much to add or subtract? He has a choice of a pre-decided amount. To determine whether to add or subtract an amount, I will toss a coin in front of you. I will then tell the researcher outside the result of the coin toss. He will add or subtract the amount corresponding to head or tail to your allocation in this room to calculate the payment that must be made to your partner. In this way, there is no way for your partner to know how much you allocated to $\mathrm{him} / \mathrm{her}$.

Are there any questions on how we keep your allocations secret? If you have questions, please raise your hand and wait for my assistant to come to you.

In the other room, your partner will be doing exactly the same activities that you are.

Let me remind you who your partner is. Those of you who were given a red number tag are paired with the person who they came with to the session today in the other room. Those of you who were given a blue number tag are paired with a stranger in the other room. None of you know exactly with whom you are paired. Only researchers knows who is matched with whom, and she/he will never tell anyone.

[Now conduct the activity. Distribute envelopes]

Please open your white envelopes and count that you all have 10 tokens.

Now put the tokens back in the envelope.

Remember, because this activity is private, your partner will never know the money comes from you. S/he will not know how much money you gave and how much you kept for yourself. Please put as many tokens as you want to give to your partner in the blue envelope and put the tokens you want to keep for yourself in the white envelope. Make sure your choice is hidden and do not discuss it with other participants in the room. We will then shortly collect both these envelopes from you. This will tell us how much you have given to your partner.

Are there any questions? Please raise your hand and I can come to you in private and explain the activity to you.

My assistant will now come to you one by one to collect the envelopes. Please keep seated as we do so. As we have explained, once all activities have been played, we will randomly select one activity for which you will receive payment. If this activity is chosen, we will select a number from this bag to select the round and the room according to which payment will be made. [Show numbers and bag]. 


\section{Taking and dictator with earned endowment}

We are now ready to begin another activity (if the second/third activity)/the first activity. Let me remind you that you may not ask questions or talk while you are here in the group. If you have any questions, you may raise your hand and I (the enumerator) or my assistant(s) will come answer your question privately. [Only if dictator game has not been played first: ] This is NOT the same activity that you just performed, so be sure to listen to the instructions carefully.

\section{Introduction and partner matching}

- This activity is performed by pairs of individuals.

- Each of you will perform this activity with someone from the other room.

- Who your partner will be depends on the color of your number tag, that was determined by a random draw earlier.

- Half of you were given a red number tag, the other half a blue number tag. Your partner for this activity is determined by the color of your number tag.

- Those of you who were given a red number tag will be paired with their spouse in the other room.

- Those of you who were given a blue number tag will be paired with a stranger in the other room. None of you will know exactly with whom you are paired. Only [researcher's name] knows who is matched with whom, and she/he will never tell anyone.

- In the other room, your partner will be doing the same activities you are.

Do you have questions on who your partner will be in this activity? If you have questions, please raise your hand and I will come to you to answer your question privately.

First, we will explain one part of this activity that might be a little confusing. Please listen carefully, and if there is anything you don't understand, do not worry, since you will have a chance to ask questions in private with me to be sure that you understand how to play.

In this activity, you will have an opportunity to earn money. Everyone in this activity will earn money that will be divided between him or herself and his or her partner. You will earn money by sorting black chickpeas out of a box. The money that you earn by successfully completing this activity will then be divided between you and your partner in the other room. While we are playing the activity in this room, your partner in the next room will also be making decisions about how he or she would divide money between the two of you that you will earn in the activity. 
Table B4: Earnings corresponding to black chickpeas collected

\begin{tabular}{cc}
\hline $\begin{array}{c}\text { Range } \\
\text { (black chickpeas) }\end{array}$ & Earning (Rs.) \\
\hline $0-19$ & 0 \\
\hline $20-39$ & 100 \\
\hline $40-59$ & 200 \\
\hline $60-79$ & 300 \\
\hline $80-99$ & 400 \\
\hline $100-119$ & 500 \\
\hline $120-139$ & 600 \\
\hline $140-159$ & 700 \\
\hline $160-179$ & 800 \\
\hline $180-199$ & 900 \\
\hline 200 or more & 1000 \\
\hline \hline
\end{tabular}

After we finish playing all the activity, we are going to pick one of the two rooms, this one or the other one. Only the decisions made in the room that we pick will count towards deciding your payment. So, either your decisions or your partners decisions, but not both, will determine how much both you and your partner take home at the end of the activity.

We will first describe how you and your partner will earn money by sorting chickpeas, and then we will describe how you and your partner will divide the other's earnings.

\section{Earning money by sorting chickpeas}

There is a large box in front of you. There is an identical box sitting in front of your partner in the next room. The box contains two different kinds of chickpeas: black chickpeas and white chickpeas. Each player has a box and a plate with their number on them.

After we finish explaining the instructions, we'll ask you to remove the lid from your box and place it on the floor. At that point, we will give you two minutes to collect black chickpeas from the box and place them into the plate. After you finish collecting black chickpeas, we will count the black chickpeas that you have in your plate. You will be paid according to the number of black chickpeas that you collect.

Please look at this poster to understand how we are going to pay you. The poster shows you ranges of chickpeas that you may collect. If you collect a number within one of these ranges, you will be paid the amount shown in the column next to it. For example, if you collect 50 black chickpeas, you will get Rs. 200. If you collect less than 20 chickpeas, you will get nothing. If you collect 35, you will get Rs. 100. Any questions? [Enumerator: read out all possible earnings from the poster put up as given in Table B4]. 
So, you will earn money in this activity by collecting chickpeas from the box. The more chickpeas you collect, the more money you earn. In the other room, your partner will follow the same procedure and earn money by counting chickpeas in exactly the same way. So the same holds for your partner: the more chickpeas your partner collects, the more money he or she earns.

You can spend up to two minutes collecting chickpeas. At the end of the two-minutes, we will ask everyone to replace the lids on their boxes. However, you are free to stop at any time during the two-minute period. If you stop before the two-minutes are over, we will ask you to put the lid back on the box. You will then bring the black chickpeas you have collected up to the front of the room, where we will count them. Your partner in the other room will also have two minutes to collect black chickpeas, will be free to stop at any time during the two minutes period, and will bring the black chickpeas he or she has collected to be counted.

While you are collecting chickpeas from the box, you will follow these rules. These are the same rules that your partner will follow in the other room.

- No one is allowed to leave chickpeas on the floor. If a participant leaves chickpeas of any type on the floor (rather than in the box) at the end of the two minutes, that participant will not be paid anything for the chickpeas that have fallen on the floor.

- Also, you cannot empty out your box and pick the chickpeas off the floor. Any participant who empties out their box onto the floor will not be paid anything for the chickpeas he or she collected.

- In addition, everyone must make sure to only place black chickpeas into the plate that we will take to count and determine how much you earn. When each participant brings their chickpeas up to be counted, we will check if there is a white chickpea in the plate. If there is, we will deduct Rs.50 for every white chickpea we find in your plate. For example, if a participant sorted out 20 black chickpeas, he would earn Rs. 100 but if the participant sorted 20 black chickpeas and also a white chickpea in the plate, he will receive Rs. 100 minus 50 i.e. Rs. 50.

- Finally, participants are not allowed to remove the box from the floor in front of them at any time while they are sorting out chickpeas. They may not tip or lift the box, as chickpeas could spill onto the floor.

So, both you and your partner will have two minutes to collect black chickpeas from the box. Both you and your partner can stop at any time, or work for the full two minutes. Both you and your partner will be paid according to the number of black chickpeas that you collect.

Before we explain the rest of the activity, we are going to let you try sorting chickpeas into the plate. Each of you can take the lid off of your box and place it on the floor. Please reach into the box and pull out one black chickpea. We will come around and verify that each of you understands the distinction between the different types of chickpeas. 
We've finished explaining how you and your partner will earn money in this activity by collecting chickpeas from a box.

Before you can sort chickpeas, we are going to invite you outside to tell us how you want to divide your possible earnings between yourself and your partner in the next room. You will tell us how you would divide all of the possible amounts that you might end up being paid for sorting out chickpeas. In the other room, your partner will be asked to do the same. We will just explain what these possible amounts are.

We will ask you to decide how to divide each other's earnings twice. Please listen carefully as this may be confusing. Once we will ask you to divide your own earnings between yourself and your partner and once we will ask you to divide your partner's earnings between yourself and your partner. Please note the distinction, in one case you will be dividing your own earning and in the other you will be dividing yours partners earnings. Is this clear to everyone?

\section{Dividing the earnings}

[randomise order of dictator and taking allocation and then read instructions for whichever is chosen first]

\section{Dictator:}

In this round we will be asking you to divide your own earnings between yourself and your partner. We will now go through all of the possible amounts that you may earn. The smallest amount that you may earn is Rs. 0, which is what you would earn if you did not collect at least 20 black chickpeas. On the other hand, no matter how hard you work, you cannot earn more than a 1000. For each possible amount that you may end up earning, we'll ask you how you would divide that money between yourself and your partner.

In this round you are allowed to keep as much or as little of your earnings to yourself as you want, it is your decision. How much you want to leave your partner might depend on how much you earn. For each amount that you earn, we'll ask you how much of it you would like to keep for yourself. We will ask the same questions to your partners, finding out how much he/she or she would like to keep to him or herself for each possible amount that he/she might earn.

Let's look at a couple of examples.

Imagine that an individual comes to me. I will fill out this sheet with them [show sheet] by asking him or her about each possible earning. For example I will ask 'if you end up earning Rs. 400, how do you want to divide it between yourself and your partner?' A possible answer of the player could be: 'I will take Rs. 200 and leave the other Rs 200 for my partner'. Then I will ask him or her: 'I want you to tell me what you would do if you earned Rs. 800 instead. How would you like to divide it between yourself and your 
partner?' A possible answer of the player could be: 'I will give myself Rs 600 and I will leave my partner Rs 200.' Then I will ask him or her: 'I want you to tell me what you would do if you earned Rs 1000. How would you like to divide it between yourself and your partner?' A possible answer of the player could be: 'I will give myself Rs 400 and I will leave my partner Rs 600.'

Different people might make different decisions. Now imagine that another player comes to me. I will ask him or her: 'Now please tell me how you want us to divide your earnings if you earn 500.' A possible answer of this other player could be: 'I will give all of the money to my partner and take nothing for myself.'

Remember, you can divide the money that you earned any way you want, the decision is yours. You can leave your partner all of your earnings, or none of it. You can do whatever you want to do.

Remember, all of you are going to receive Rs. 1000 as participation fee for attending the activity session. As we have explained, in addition to the participation fee, once all activities have been played, we will randomly select one activity for which you will receive payment. If this activity is chosen, we will select a number from this bag to select the round and the room according to which payment will be made. [show numbers and bag]. The payment to you for this game will be after any penalties have been deducted. Let me also remind you who your partner is for this activity. For those of you who have a red tag, your partner is whoever you came with in the next room. For those of you who have a blue tag, your partner is a stranger in the other room. Only [researcher's name] knows who you are matched with if you have a blue tag, and she/he will never tell anyone.

Are we ready to begin? This may take some time, and you must sit quietly while you await your turn. [Answer any questions and then begin calling subjects to you by ID number on their tag whenever the enumerators recording the choices are ready. It is very important that one enumerator makes sure that everyone is seated and not talking at all.]

\section{Taking:}

In this round we will be asking you to divide your partner's earnings between yourself and your partner. We will go through all of the possible amounts that your partner may earn. The smallest amount that they may earn is Rs. 0, which is what they would earn if they collect at least 20 black chickpeas. On the other hand, no matter how hard they work, you cannot earn more than Rs. 1000. We have played this activity many times, and no one has ever earned that much. For each possible amount that they may end up earning, we will ask you how you would divide that money between yourself and your partner.

In this round you are allowed to transfer as much or as little of your partner's earnings to yourself as you want, it is your decision. How much you want to leave your partner might depend on how much your partner earns. For each amount that your partner might earn, we'll ask you how much of it you would like to transfer to yourself. We will ask the same questions to your partners, finding out how much he or she would like to transfer to him or 
herself for each possible amount that you might earn.

Let's look at a couple of examples.

Imagine that an individual comes to me. I will fill out this sheet with them [show sheet] by asking him or her about each possible earning. For example I will ask 'If your partner ends up earning Rs. 500, how do you want to divide it between yourself and your partner?'. A possible answer of the player could be: 'I will take Rs. 200 and leave the other Rs 300 for my partner.' Then I will ask him or her: 'I want you to tell me what you would do if your partner earned Rs. 900 instead. How would you like to divide it between yourself and your partner?' A possible answer of the player could be: 'I will give myself Rs 600 and I will leave my partner Rs 300.' Then I will ask him or her: 'I want you to tell me what you would do if your partner earned Rs 100 . How would you like to divide it between yourself and your partner?' A possible answer of the player could be: 'I will give myself Rs 50 and I will leave my partner Rs 50.'

Different people might make different decisions. Now imagine that another player comes to me. I will ask him or her: 'Now please tell me how you want us to divide your earnings if you earn 500.' A possible answer of this other player could be: 'I will give all of the money to my partner and take nothing for myself.'

Remember, you can divide the money that your earns any way you want, the decision is yours. You can leave your partner all of their earnings, or none of it. You can do whatever you want to do.

Remember, all of you are going to receive Rs. 1000 as participation fee for attending the activity session. As we have explained, in addition to the participation fee, once all activities have been played, we will randomly select one activity for which you will receive payment. If this activity is chosen, we will select a number from this bag to select the round and the room according to which payment will be made. [show numbers and bag]. The payment to you for this game will be after any penalties have been deducted. Let me also remind you who your partner is for this activity. For those of you who have a red tag, your partner is whoever you came with in the next room. For those of you who have a blue tag, your partner is a stranger in the other room. Only [researcher's name] knows who you are matched with if you have a blue tag, and she/he will never tell anyone.

Are we ready to begin? This may take some time, and you must sit quietly while you await your turn. [Answer any questions and then begin calling subjects to you by ID number on their tag whenever the enumerators recording the choices are ready. It is very important that one enumerator makes sure that everyone is seated and not talking at all.]

Now, you have two minutes to collect chickpeas from the box in front of you. Is everyone ready to begin?

[To the enumerator: conduct the sorting activity] 


\section{Construction of 'female agency' index}

The variable 'Decide alone' is constructed using the response to the following survey question: Who in your household usually makes decisions about the following?

1. Clothing and footwear

2. Medical treatment

3. Recreation and travel

4. Visit friends in the neighbourhood

5. Make small purchases for yourself (e.g. clothes)

6. Make small purchases for others in the household (e.g. kitchen utensils)

7. Join a credit group/committee

8. Invest surplus money

9. Your marriage

10. Loan from an organisation

- Each item above is coded as 1 if the woman reports deciding alone and 0 otherwise and then added to form the variable 'Decide alone'.

The variable 'Not allowed work' is constructed using the response to the following survey question: Why are you not actively seeking paid work?

- 'Not allowed work' takes on the value 1 if the woman reported not being allowed by husband or father; and 0 otherwise, in response to the following question:

'Female agency' is an index created out of 'Decide alone' and 'Not allowed to work' using Principle Components Analysis. 